\title{
Entrepreneurship and territorial behavior. How to exercise competitiveness in sustainability in Europe
}

\author{
Maria Prezioso ${ }^{1}$, Maria Coronato ${ }^{2}$ \\ ${ }^{1}$ Dept. Science, Technology and Education (STF), University of Rome "Tor Vergata", Rome, Italy \\ ${ }^{2}$ Ph.D. in Economic Geography, Dept. Human and Education Sciences (DSUF), University of Sassari, Sassari, Italy
}

Email address:

maria.prezioso@uniroma2.it (M. Prezioso),coronato.maria@gmail.com (M. Coronato)

\section{To cite this article:}

Maria Prezioso, Maria Coronato. Entrepreneurship and Territorial Behavior. How to Exercise Competitiveness in Sustainability in Europe. Social Sciences. Special Issue: Geographical evidence in changing Europe. Vol. 3, No. 4-1, 2014, pp. 28-45.

doi: $10.11648 /$ j.ss.s.2014030401.14

\begin{abstract}
The paper focuses on territorial impacts of the European policy with regards to the enterprise systems in the last decade and how the effects of this policy could have irreparable modified the enterprise network relationships (socio-functional and interrelated/cohesive) in regions. This suspicion has suggested European choices include the territorial dimension in the development directions by the intra and inter-regional co-operation. The searching new forms of balanced growth for enterprise is the future objective; it could be followed by assuming a territorial polycentric cohesive organization. Important European documents, like Europe 2020 Strategy and Territorial Agenda (2011), stress this orientation. A critical review of Economic Geography literature with regards to main localisation theories of enterprise opens this contribution, in order to accompany the reader in understanding of new strategic parameters able to measure 'the regional productive capability' of enterprises in the framework of European recent directions. By using innovative methodologies, the performance of enterprise systems and networks looking at these parameters, highlights European specific territorialised typologies of behaviour. Finally, some policy recommendations are suggested in this direction in order to improve the regional productivity, as well as the employment in relation with to specific economic-social-environmental parameters of cohesion and competitiveness in sustainability, looking at the regional productive capability of Small/Medium Firms (SMFs) in Europe with regards to main pillars of the 2014-2020 Strategy.
\end{abstract}

Keywords: Enterprises’ Economic Geography, European Competitiveness, Sustainability

\section{Sustainable and Economic Cohesive Development Versus Economic Growth of Enterprises Systems and Networks}

The review and comparison of relevant theoretical/academic literature identify key concepts and definitions with regards to competitiveness and sustainability, and, more recently, to cohesion.

In the $1990 \mathrm{~s}$, the literature on competitiveness, sustainability and cohesion is developed under different and no linked scientific domains; the research on the competitiveness performance concerning enterprises is the largest and more dynamic. Since the 2000s, interdisciplinary relationships among these three concepts are developed.

Initially, competitiveness is considered by different forms of access to foreign markets and as one of the main factors of the theory of international exchange the study of the behavior and strategy of the enterprise. The basic causes of competitiveness were to be studied according to diverse starting resources and different technological levels, in relation to scale performances and to the change of the factors prices and assets [4, 16, 20, 32].

A few works only extend the analysis to the role of the access procedures to foreign markets (internationalization) ${ }^{1}$. The internationalisation of the enterprises was only one of the components influencing the firm's competitiveness and its role could be estimated only in comparison to that of other traditional competitiveness factors. For example, trough the microeconomic analysis, competitiveness

\footnotetext{
${ }^{1}$ i.e. the researches on Mediterranean regional economies, where small and medium enterprise is dominant $[63,84]$; or the ones that apply the "real option theory" [21 ]introducing the concept of sunk costs (information costs, opportunity costs and travel costs of the human resources).
} 
appears as the level of efficiency of the enterprise ${ }^{2}$, directly correlated to the level of ownership concentration [76] and its relative different impact on the firm's performances as a function of its dimension $[58,45]$.

These considerations (more empirical than theoretical) permitted to take into account the huge differences in the various countries across Europe in this respect; and to understand that a balanced structure of companies was a buffer against rapid changes in the economy caused by ordinary business cycles and from structural ones (causing altered competitive advantages) of the economy as a whole.

While, by programming documents, as the Lisbon Strategy ${ }^{3}$, the relationship among performance, financial structure of firm and market possibility to access to financial source by market is underlined. The main hypothesis was that "financial pressure" produces improvements in the management accuracy and firm's performance $[40,39,1]$.

The literature on this topic focused on medium/large size firms and listed companies into several categories, through theoretical models that tried to explain the determinants of the capital structure and its influence on the process of management decision: i) tax shield, ii) conflict of interests and information asymmetry costs between shareholders and creditors [40, 38, 33], iii) information asymmetry costs between managers and shareholders, iv) financing strategies as a "signal" of the expected profitability in a context of informative asymmetry $[68,6,56,16,74]$; v) financial choices oriented by strategic decisions taken in the oligopolies contexts $[72,7,17,80]$; vi) financial choices taken in contest of share raids $[34,78]$.

The asymmetric information generated rationing in Europe, also because it modified the distribution risk-return of the Lisbon Strategy projects, that could lead the credit system refusing the supply of capital and generating a divergence between the supply and the demand [77]. Competitiveness becomes a typical economic concept and it was usually measured as the advantage of firms as compared to their competitors in both the domestic and international markets, focusing interest at the macroeconomic level [53, 62]. Authors like Lipschitz and McDonald [48] measured

\footnotetext{
${ }^{2}$ In that framework, the relationship between exportations and performance was the main indicator to measure the enterprises' competitiveness, its positive effect on the enterprise effectiveness [70, 54, 77] and profits [1].

${ }^{3}$ The Lisbon's Strategy was agreed to promote and support the transition towards a competitive knowledge economy, able to bring occupancy, growth and social cohesion, in compatibility with environmental respect; the application of common trends of economic policy to be measured by structural indicators; reforms applied through integrated strategies across all the different sectors traditionally referring to competitiveness; growth in networks and high quality knowledge through national and regional investments; competitiveness of the industry and service sectors (regulations, general policy laws, action plan on environmental technologies), active ageing of the working population (permanence in labour, e-learning, welfare); Its aim was to make the EU "the most competitive and dynamic knowledge-based economy in the world capable of sustainable economic growth with more and better jobs and greater social cohesion", by 2010 .
}

the competitiveness of a system in terms of real exchange rate.

Although authors as Helleiner [35] and Krugman [44] have criticized the assertion of economy-wide competitiveness, this formula stood out because it included the measure of competitiveness by cross-countries performance analysis. Therefore, it is important to choose variables able to measure performance in quantitative or qualitative terms ${ }^{4}$.

By Lisbon Strategy [29], an alternative use of the concept of competitiveness emerges. It is finalized to understand the competitive relations between enterprises and growth, because it was clear that macroeconomic conditions, such as a high level of education, high attitude to manage competitive market conditions and high level of optimization in the use of natural resources could influence the performance of productive specific sectors. Nevertheless, since these conditions could only be studied by the relations established at micro level, the competitiveness reinforced its weight in the microeconomic analysis, strictly linking the concept to local economic theory by the literature on the production processes and the choice of the enterprises to increasing profit [60].

From the microeconomic point of view, literature had great influence, as this typology of territorial aggregation can help the competitiveness of firms starting from the local context.

Even through research on the industrial districts have always been an eclectic domain, it had the merit to introduce the concept of "territory" as variable within the economic analysis, while the use of concepts as growth, competitiveness and agglomeration made these studies to the original industrial district model provided by Marshall [54].

From geographical point of view, all of features depicted by Marshall in the model of industrial district are subsumable under the notion of agglomeration, which suggests that the 'stickiness' of a place can be found not in the individual localisation calculus of firms or workers, but in the external economies available to each firm from its spatial conjunction with other firms and suppliers of services.

Therefore it is not surprising that many disciplines, from economics to sociology and geography, have investigated the topic of industrial districts both in economic terms and territorial ones beyond the traditional microeconomic approach, that studies the dynamic of production units without reference to their positioning in the geographic space (the territory) $[68,64]$. So, the main critical issues are related to two fundamental questions: i) the distinctive structural characteristics (economic and institutional specialization, relations, organization of firm, ) that turn on an area in industrial district; ii) the effects on the firms that take part of the industrial district.

\footnotetext{
${ }^{4}$ A possibility, generally used, is to analyse the growth of GDP (Growth Domestic Product) under the hypothesis of a causal relation between competitiveness and economic growth.
} 


\subsection{The Porter's Contribution to Evolution of Topic}

By analysing the competition of the production systems, the contribution of Michael Porter is fundamental for the evolution of the competitiveness concept in Europe. The competitive advantage of an enterprise is described by Porter [62] marking one abrupt breach with the theoretical instruments of the traditional planning and with the methodology of transaction costs. The work of Porter also sets attention on the importance of the territorial dimension in development.

Anyway, the true origin of the competitive advantage of an enterprise is the local dimension (or milieu) in which the enterprise is placed. The territory closer to the enterprise will settle many of the markets of inputs, on which the enterprise can rely for supply, the information that guides strategic choices as well as incentives and pressures on the enterprises, in order to innovate and accumulate know how or resources in the time. Competitive advantage can reside both in the territory and the single enterprise. Porter denies the hypothesis of the mutual extraneousness between enterprise and territory, in order to establish a more complex dialectic: the territory/environment leaves off being a fixed objective, in order to become the "product" of the strategic action of the enterprise.

In his approach Porter places the enterprise and the production, defining two concepts: the chain of the value and the competitive environment. So, enterprise is something more of the simple sum of its activities. The chain of the value of firm is a system of interdependencies, a net of activities and connections.

The generation of economic value is not a phenomenon that can be observed in an isolated link of the chain, but it demands the co-ordination and the competitive capability of all activities, which produce a competitive advantage in force of their complementary set-up. Economic competition does not display therefore as the contrast among isolated enterprises, but among alternative chains of the value. The progress for Porter comes from the process of movement along the chain of the value towards types of advantage which are more sophisticated.

So competitiveness it is not limited to single contenders but it extends to many territorial actors (concurrent effectives, suppliers, contenders upgrades them, etc.) that are situated along the chain of the value and exactly define the extension of the activities that the enterprise carries out to compete in a specific field.

With the competitive environment notion, Porter recovers in the economic analysis, two fundamental elements: history and geography. History is fundamental in order to comprise dynamics of the forces on the ground and their development ${ }^{5}$.

\footnotetext{
${ }^{5}$ The competitive atmosphere of an enterprise has changes in the time: since the competitive games are changing and intensifying and the technological complexity are growing, if the enterprise if it wants to remain competitive, it must continuously renew its own abilities to control and co-ordinate.
}

Geographically, the competitive environment is inclined to extend, by integrating and differentiating the enterprises, so that the localisation strategy is an integral part of the competitive action of firms.

Porter affirms that competitive advantage depends by both the internal factors of the enterprises, and the territory where the enterprises are inserted. So the search for competitive advantage cannot disregard the interaction with the local systems and their actors.

This assertion leads to a fundamental point of Porter analysis: if the advantage is achieved and maintained through a localised process, the reasons of the success of some competitors must be searched for in the localised contexts (states, regions) where they operate.

In Porter's studies, this greater role for the territory as a competitive element has emerged from a large sample of industries in ten countries. The ability of an enterprise to innovate and to expand depends on four characteristics of the territory (from which the famous "diamond". See the light grey parts in the Fig. 1); these characteristics have not a specific geographical meaning:

- Strategic localization

- Local demand

- Integration with regional cluster.

- Human Resource

Moving from the competitiveness of the enterprises to competitive advantage of nations Porter revises the diamond by including other fundamental elements:

a. factor conditions (i.e. the nation's position within factors of production, such as skilled labour and infrastructure);

b. demand conditions (i.e. sophisticated customers in home market);

c. related and supporting industries;

d. firm strategy, structure and rivalry (i.e. conditions for organization of companies, and the nature of domestic rivalry).

Porter argues that the best management styles vary with industries. In addition some countries may be oriented toward a particular style of management. Those countries will tend to be more competitive in industries for which that style of management is suited ${ }^{6}$.

Therefore with regard to the Lisbon and Gothenburg Strategies ${ }^{7}$, and even more in respect of the Europe $2020^{8}$,

\footnotetext{
${ }^{6}$ Moreover Porter argues that intense competition spurs innovation, but also that in presence of international competition there are enough differences between companies and their environments to provide useful excuses to managers who were outperformed by their competitors.

${ }^{7}$ The Gothenburg's Strategy [28] was agreed to support sustainable public policies in order to contrast and reduce climate change, public health risks, poverty and social marginalization, population ageing, natural resources depletion, pollution, traffic congestion and use of the territory; to promote an economic growth that would keep pace with social progress and environmental respect, also in terms of costs.

${ }^{8}$ Europe 2020 [25] puts forward three mutually reinforcing priorities:

- Smart growth to develop an economy based on knowledge and innovation.

- Sustainable growth to promote a more resource efficient, greener and
} 
the diamond's model needs to be updated (see red parts in the Fig. 1), in order to comply with the directions emerging from new economics and social models; then it is necessary ro include additional categories of elements as: Innovation and Technology, Global/local interaction, Quality (process, environmental, production, service ones), Efficient use of Resources and Funds.

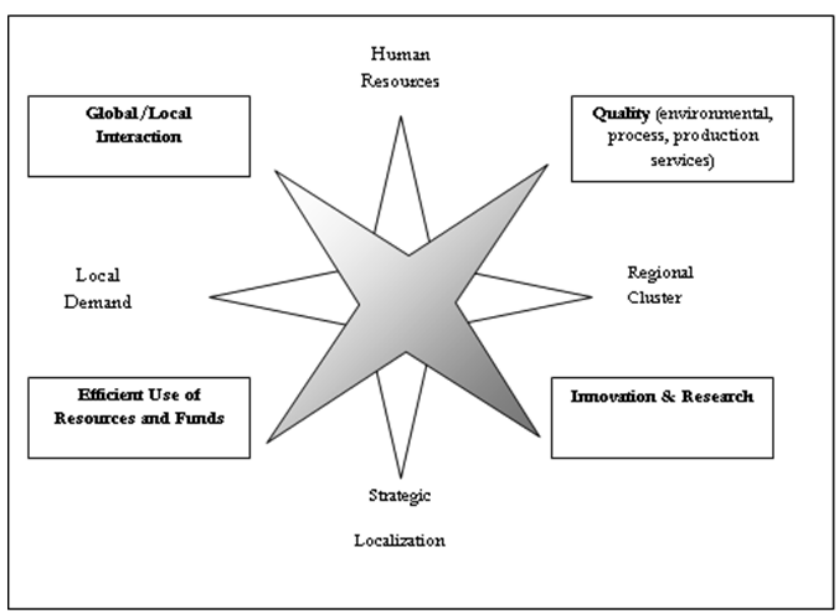

Figure 1. The revised Porter's Diamond Original Model for the competitive advantage [65]

The Original Porter's Diamond Model is represented in white. Components that modify the Porter's Diamond are represented in light grey.

Since 2007, all territorial communities that have worked as "system" have promoted, in the analysis of competitiveness, the introduction of the social capital's concept, recently back in vogue and expanded as "territorial capital" $" 9$ [9, 10].

The ability to incorporate the territorial capital into the local development strategy as key characteristic of the growth model has been rather limited in years, and it only emerged after the introduction of the territorial cohesion concept within the regional policy ${ }^{10}$.

more competitive economy.

- Inclusive growth to foster a high-employment economy delivering social and territorial cohesion.

${ }^{9}$ Territorial capital was originally proposed in a regional policy context by OECD in its Territorial Outlook [61] and, recently, it was relaunched by DG Regio of the Commission of the European Union: "Each Region has a specific 'territorial capital' that is distinct from that of other areas and generates a higher return for specific kinds of investments than for others, since these are better suited to the area and use its assets and potential more effectively. Territorial development policies (policies with a territorial approach to development) should first and foremost help areas to develop their territorial capital" [27: 1],. The economic role of territorial capital resides in enhancing efficiency and productivity of local activities. In a stylised, potential treatment of the single elements of territorial capital, efforts should be addressed towards the possibility of a quantitative measurement of each of them; impossibility of a direct measure implies to equate the effects of territorial capital to "technological progress" in a production function - but this would only represent a measure of our "ignorance".

${ }^{10}$ In order to completely comprise the topic of the competitiveness, the contribution of the "empirical literature" turns out to be fundamental for
This aspect was also stressed in the microeconomic analysis of competitiveness related to the dimensional impacts of competitiveness. Some contributions on enterprise economy matter [57, 46, 47, 41] assert as the peculiar characteristics of the territorial systems can strongly influence the work organization and productive dynamics of enterprises, favouring both greater flexibility and increase in production and employment.

Economic Geography has contributed to elaborate theories and models that include these topics, especially to put them in light of the sustainable development. New studies in this field, overtaking the concept of geographical space (understood as indifferent and homogenous extension), introduce territory (understood as a relationships' system among environmental, social and economic components) as fundamental integrated variable for each policy, localisation and planning choice, confirming the inclusion of new parameters within the governance's rules orienting enterprise behaviour.

Some territorialised performances of enterprise systems and networks (referring to entrepreneurship capability) become examples of an effective regional behaviour since they are working in relation with the process of the organisation and coordination of actors to develop regional capital.

Following these evolutions entrepreneurship and regional development, territorial organisation and dynamic, their different patterns changing across space and time, are now strongly significant.

as specific and characteristic components of places for the competitiveness.

On the other hand, the territorial capital that includes socio-economic, cultural, historical and environmental heritage, considered as specific localised asset for competitiveness, is at the basis of the regional performance focusing on differential gear component of regional growth.

However we can recognize territorial assets from different scientific fields: in the spheres of economy (R\&D, human capital), of economic geography and of urban-territorial structure (presence of large agglomerations, level of accessibility, peripheral areas, etc.).

As European Union requires to be competitive, it is necessary that territorial entrepreneurship and regional sustainable development policies work together by using common assessment processes and tools. Decision makers, stakeholders, practitioners, citizenships have to participate in the production of ex ante and ex post evaluation scenarios in order to reduce negative effects of policy choices within a specific territorial context and its entrepreneurship system, building on regional differences and potential to obtain new economic and external advantages for productivity.

Therefore this requires a new understanding for both

verifying the many reflections arising from the case studies to the aim of estimating if valid conclusions for some particular areas can have a general character. 
conceptual development of competitiveness and territorial needs to combine business and enhance sustainable development.

\section{Changes in Conceptualisation of Competitiveness}

From 2000 to day, the influence of European discourse on competitiveness concept increased as well as the amount of national and regional empirical studies; this vague affected directly territorial and spatial planning and it is coupled with a similar dynamics to include in planning rationale 'new' concepts as cohesion, sustainability, polycentrism, etc.

These notions, particularly sustainability, have already been considered by business economy studies and more recently by green economy scholars from different domains; but in the past the social, regional and territorial disciplines used these concepts mainly 'against' the economic theory that considers environment, space/place, cohesion as factors to subordinate to the production function of firms in order to survive, compete and grow in the international market.

At present, several evolutionary and applied theories, emerging form sustainability science, offer interesting suggestions for territorial development of enterprises in Europe. Among them, it is useful to mention [50, 14, 46]:

- $\quad$ the industrial symbiosis model useful to conceptualize and to operationalize the relationships between firms and natural environment;

- ecological footprint model that measures the complex of resources needed/consumed to produce goods and services;

- environmental vectors or domains approach, where different compartments of the productive system are analysed considering their trends over time.

Environmental sustainability becomes an option within development theory when Scott and Storper [75] started with the assumption that the regional scale is the geographic basis of the economic development, and the external economies are necessary to make domestic businesses competitive. These remarks were considered in the context of localised interdependencies that underline the persistence of areas of efficiency and innovation, of agglomerations of capital and labour in the economic development.

The idea that places compete as much as firms, derived from Porter work and the New Regionalism theories [69] starts from the belief that regions as well as cities could compete at the global scale, adopting a business organisation.

Cheshire and Gordon [13, 15] clearly speak of 'territorial competition': this phenomenon particularly would affect the cities, and would consist in working out policies for local economic development. The reference to the local scale becomes important as it implies the idea that policies must be aimed to keep before a favourable environment for domestic business growth for attracting international capital, In the space of ten years, the territorial (and no logger spatial) competition phenomena started to studied, and become the "objective" of territorial policies.

Following a large debate stressing alternatively or complementary on competitiveness and sustainability as typical concepts within economic and entrepreneurial domain, literature identified these notions as aims for both regional and business development; nevertheless scholars do not agree on an unique definition nor common rules for the enterprises' behaviour [42].

With respect to European Commission documents we can observe two similar (but not identical) definition referring to nation and regions as the factor that can assure 'increasing' quality of life by means of available employment. The first definition is from [22: 6]: «high and rising standards of living of a nation with the lowest possible level of involuntary unemployment, on a sustainable basis»; the second document, directly devoted to the productivity, affirms that competitiveness is «a sustained increase in real incomes and in the standards of living of regions or nations, with jobs available for all those who wish to find employment» [23: 4].

However, it should be noted that this concept of competitiveness is different from the narrower concept applied to competitiveness of enterprises in which domestic factors are less dominant determinants [44, 42]. Instead considering quality of life as complex factor allows to identify territorial diversity and sustainable development as important characteristics for competitiveness of European regions. In the light of applied researches results, this diversity would able to generate more options in global competitions (see ESPON Programme 2006) and would give element on which Europe could found recovery policies to manage impacts and effects of the global crisis.

However, since 2006, many discussions focused on the rigor to apply (in contrast with the more argued austerity) in the economic-territorial action of states, regions and enterprises. By the fundamental contribution of geography, this severity in budget management it has been translate in empirical solutions to elaborate development policies. International, national and regional trends are now interpreted in a different way, stressing the need to align the future cohesion policy to the 2013 goals and to the Europe2020 aims, and to concentrate funds on lagging regions.

The review of operation of banking system concerning credit for business investments and employment re-launching is a fundamental part of this programme. Before and after 2009, a lot of words were and are spent about the European policy capability to achieve these goals; however only recently the European policy produced a document, the Territorial Agenda, in which the idea of an integrated development of regions is organized around the need to develop 'territorial and economic strategic planning' With the aim of creating a new balanced - sustainable and cohesive - growth, using, it is necessary to include in planning practice, instead of the traditional ones, the new conceptual terms and phenomena (as polycentrism, urban 
drives, rural areas, ultra-peripheries, and so on) emerged from applied researches [30, 31].

Territorial cohesion and sustainability objectives stress on search of efficient enterprise's behaviour to be competitive. Thus, the theoretical study of geographical phenomena is attended to engage and to adopt solutions at local level for several polices (Energy, Climate Change, Demography, Global Economic Competition, Accessibility, Health, Social inclusion, Urban habitat, etc.); their integration in a strategic plan involving enterprises is considered a fundamental basis of competitiveness.

The shift of planning policy paradigm through territorial cohesion and integration, asks for new and more complex localisation theories. They should be able to take in account both specific characteristics of places (social, cultural, economic, technological, and so on) and the heritage and value (territorial capital) of enterprises within the whole EU; they also have to be harmonise - specially referred to the sustainable development of the cohesion policy - testing them from the territorial point of view.

Different geographical scales and the diversity of national/regional legislations need to be re-considered, because they produce a substantial gap in applying European policies. Some examples of a co-operative, strategic and integrated vision between enterprises and territorial development come from EU planning experiences (e.g. expressly and firmly fixed in Germany, Finland, Denmark, Sweden and UK). They have included economic, social, and cultural aspects in addition to environmental concerns.

Focusing on regional performance, it becomes clear that it differs from both national competitiveness and competitiveness at the level of the firm. In order to distinguish between the various components of regional competitiveness, some research [57], reveal competitiveness by indicators of the regional performance with regards to the regional institutional targets as well as the quality of life and standard of living.

The European attitude towards bottom-up purposes is pragmatic in front of outputs of their experimental application in regional plans, where stakeholders/enterprises participation is considered an important added value in order to obtain positive results.

A virtuous combination of this approach is represented by the Danish experience of "industrial symbiosis" in the field of Industrial Ecology Growth ${ }^{11}$ and Green Economy.

To find solutions that combine business and territorial needs to support sustainable development has become the main priority of the competitiveness model promoted by European policy as well as the achievement of better quality

\footnotetext{
${ }^{11}$ It is based on the use of materials and energy flows that are involved in industrial processes at different geographical scales. It considers the industry as a cluster system and how to achieve competitive benefits involving physical exchanges of materials, energy, water and/or by-products. Key points of the Industrial Symbiosis are collaboration and the possibility of synergies offered by geographic proximity, overcoming the physical dimensions of the Industrial Park to expand and become an Eco-Industrial District.
}

of life, as we will show in the following part.

\section{External Factors Influencing the Territorial Competitiveness of Enterprises}

Within the Economic Geography field, "guidelines factors" are studied in the economic choices theory. Starting from the XIX century, the localisation theory for the enterprise system was developed as an early response to the lack of consideration of space in traditional economic analyses. Originally developed by Alfred Weber [85] and Walter Isard [37], the localisation theory has primarily focused on developing quantitative models finalised to search the "optimum" of industrial localisation (production site), on the basis of its economic distance from/to market and supply site (raw materials, energy, manpower and final goods). The hypothesis is firms will tend to set near market when the whole of costs of the final goods exceeds costs of the production inputs. Conversely, firms will tend to set near input sources when costs of raw materials are larger than the ones of final good. However the localisation theory cannot provide alone a full theory of regional economic development; other models based on the calculus of transport cost related to the physical distance have highly affected the following theories of economic growth and development, particularly in the field of regional science [37] but also the so called New Economic Geography [32].

Economists, since Marshall [54], have pointed out as industries might work as cluster minimising internal cost. Instead, firms might work as cluster to take advantage of external economies that result from close proximity to a large number of other firms. Following Hoover [36], these external economies may include: i) agglomeration economies that result from firms working in the same sector and in the same area, and ii) urbanization economies, which result from the sharing of costs between firms and urban inhabitants. These external benefits increase by the growth of the number and the outputs of localised firms; they are usually named as external economies of scale .

Economists continue to disagree over the nature and cause of these external economies, but broadly speaking, knowledge spillovers, labour pooling, and economies in the production of intermediate inputs have all been cited as contributing factors. Because external economies of scale are characterized by both positive externality effects and increasing returns to scale, traditional competitive market models have tended to ignore these effects [19].

In the 70ies internal factors that generate external economies of scale (economies of industrialization, economies of agglomeration, economies of urbanisation) emerged as driving external factors for business competitiveness: the relative position of the site, the presence of similar competing firms in a national market to share the cost of services, the existing infrastructural endowment (primary and secondary urbanisation), the type 
of corporate culture, the level of population's reception and involvement in the project became a source of competitive advantage.

The degree of efficiency resulting from all of these conditions made possible to achieve broader economic objectives such as: a) availability of skilled labour; b) adequate level of technology; c) speed of information; d) proximity to market; e) reduction in procurement costs. These conditions have fostered the emergence and the spread of the so-called industrial districts in Europe, and especially in Italy.

The presence of these communities, that work as a "system" [64], it seemed to favour, as an intermediate output, the creation of common institutions and cooperatives that can generate a climate of mutual confidence (social capital) which is important for development aims.

Thus, business competitiveness becomes a multi-disciplinary concept [66], no longer tied only to traditional factors but to new territorial external factors such as knowledge and innovation, and localization/specialization effects. The factors impacting on territorial economies of scale become:

- $\quad$ territorial attractiveness

- continuous qualitative improvement

- cultural and social heritage enhancement

- $\quad$ sustainable use of resources (natural, economic, social)

- $\quad$ preventive assessment of policies, programmes and projects

These approach has some common with the endogenous growth theory $[69,12,43,73,74]$.

Schumpeter [74], for example, was the first to point out that the process of innovation is a largely race for monopoly control over the stream of rents from new innovations, which are essentially public goods once introduced. Arrow's [3] "learning-by-doing" framework is within the neo-Schumpeterian tradition by arguing that firms can gain monopoly power over new knowledge through experience in internal production. Innovations are modelled as declining costs that are functions of a firm's previous investments. If a firm can internalize these costs, it can gain a competitive advantage.

System of localised externalities, both monetary (where advantages are from market transactions) and technological (when advantages are exploited by simple proximity to sources) can be:

- a system of localised production activities, traditions, skills and know-how;

- a system of localised and proximity relationships, constituting a "capital" -social, psychological and political - in that it enhances static and dynamic productivity of local factors,

- a system of cultural elements and values, which attributes sense and meaning to local practices and structures and define local identities; they acquire an economic value whenever they can either be transformed into marketable products - goods, services and assets - or boost internal capability of exploitation of local potentials;

- a system of rules and practices defining a local governance model.

Accordingly, OECD [61: 15] rightly indicates a long, sometimes plethoric but well-structured list of factors as the determinants of territorial capital, going from traditional material assets to more recent immaterial ones: "These factors may include the area's geographical location, size, factor of production endowment, climate, traditions, natural resources, quality of life or the agglomeration economies provided by its cities, but may also include its business incubators and industrial districts or other business networks that reduce transaction costs".

Looking for the European documents, and in particular for the ones about the Lisbon/Gothenburg strategies, we understand that competitiveness in Europe must have some borders and particular guidelines; as well as that enterprise systems must be competitive in sustainability [65]. This concept means for EU enterprises:

- "high and rising standards of living of a nation with the lowest possible level of involuntary unemployment, on a sustainable basis" [22, 65];

- $\quad$ regional competitiveness factors include issues such as innovation, information and communication technologies (ICT) ${ }^{12}$, and environmental protection;

- $\quad$ the regional and national territory cannot be regarded as an undifferentiated space of the social and economic action, but rather as a physical place whereby to measure and monitor the territorial capability of competitiveness;

- $\quad$ the territory becomes a parameter to measure virtuous solutions supporting the regional entrepreneurial structure, in terms of environmental sustainability, improvement of cohesion and integration between different territorial actors (whether institutional or not);

- $\quad$ some management capabilities (components) able to guarantee territorial competitiveness are needed: awareness of its innovative capacity; organisation in networks; ability to integrate the different sectors and levels of activities, to cooperate in and with other territories, to involve different public and private subjects and institutions; to have both a global and coherent vision while respecting the use of local resources and to organise international, European, national, regional policies from a subsidiary point of view;

- market competition has to be sustained, through those endogenous factors that differentiate the territorial whole/system (mix of social, cultural, environmental, economic indicators influencing the regional ranking within Europe and in the international context)

"Information and Communication Technologies, ICT, refers to technologies that provide access to information through telecommunications. It is similar to Information Technology (IT), but focuses primarily on communication technologies. This includes Internet, wireless networks, mobile phones and other communication media. 
- some cheap raw materials have to be linked to entrepreneurial vital and innovative factors within a stable social context

- $\quad$ market competition has to be faced creating scenarios capable of guaranteeing environmental, social, cultural and economic sustainability

- $\quad$ confidence in internal co-operation between different subjects and the European Community level as regards environmental protection and development

All these elements also mean cohesion, which is typified by the behaviour of European institutions and enterprises. For these subjects the concepts of territorial cohesion and quality have successfully become synonymous in sustainable competitiveness. The achievement of certifications like ISO $^{13}$ or EMAS ${ }^{14}$ testifies and measures this behaviour, followed by the enlarged concept of social responsibility (for example Territorial more than Corporate Social Responsibility) considered as a useful and necessary instrument of cohesion between entrepreneurship goals and institutional aims.

\subsection{The Added Value of Sustainability for Firms in the Light of the Global Market}

Environment has now become a priority of European policy both generally and in support of business competitiveness. Then it is necessary to internalized this priority (EMAS Regulation, ISO 14001, ISO 1440 series, EU ROHS ${ }^{15}$ and so on) and achieve compliance with specified shared objectives.

However, the whole of the relationships between productive organisations and the territorial system chosen for the implementation of the economic activity has changed the concept of environment, no longer considered only in terms of services at local (or district) level of which firms benefit in terms of positive externalities and (direct and indirect) competitive advantages, but rather as an endogenous variable of the business activity, to be included

13 International Organization for Standardization, International Organization for Standardization, is the Standards Organization that operates at international level to establish reference standards through mechanisms of consensus involving all stakeholders. ISO standards specify the requirements for state of the art products, services, materials and systems, and for good conformity assessment, managerial and organizational practice.

14 EMAS, Eco-management and audit scheme. EEC Regulation (No. 1836/93) and is currently EC Regulation no. 1221/2009 Membership in a Community Allows the evaluation and monitoring of potential environmental effects and determine the degree of environmental efficiency of economic activities, industrial and manufacturing activities at a site. The Regulation also identifies environmental regulations applicable to the activities that take place, and compliance with, as well as the identification of improvements in environmental performance on the technical and managerial.

${ }^{15}$ EU ROS, European reactive oxygen species. It will bring together multi-disciplinary experts to enhance the competitiveness of European research. By applying fundamentally new approaches it will generate advanced knowledge and translate this into novel applications ranging from medicine to crop science. in the industrial production process.

In fact, any intervention aimed at the growth of the economic system generates a series of impacts on the territory where the firms operate, resulting in the gradual depletion of the same resources that attracted the firm activity.

Hence, the goal of sustainable development is to find suitable solutions to be compatible with both the needs of business development, and those of the territorial system.

Investing in sustainability, contrary to common thought, represents a huge source of income (not just economic) for all those business organizations that are able to move into new markets, increasingly characterized by sustainable products and processes, with considerable flexibility and dynamism.

The right balance (Figure 2) between environmental protection and economic growth defines environmental quality as a means of obtaining production benefits through the internalization of the fundamental rationale of sustainable production [63].

In fact, this is not only referred to an increase of the business size (growth), but to a balanced and progressive growth over time (development).

The relationship established between environmental quality and business development is shown in Figure 1 which display as a decrease in environmental quality (environmental curve), due to the use of resources, enhances business development (firm curve), but also as the two curves are inversely proportional to each other.

The point of equilibrium, that is sustainability, occurs when environmental quality decreases without exceeding the limit of sustainability, while still ensuring a growth in business quality.

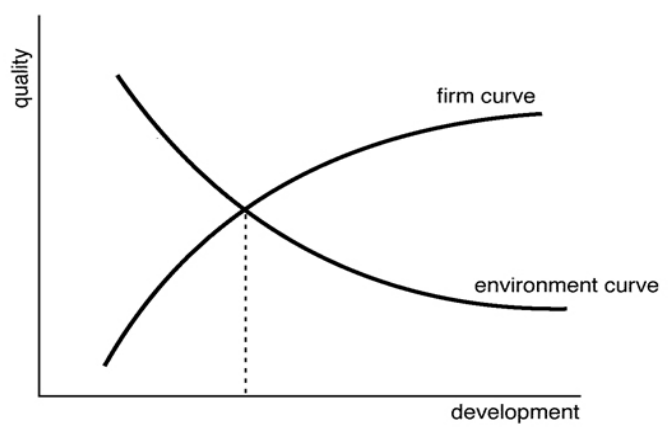

Figure 2. Relationship between Environmental Quality and Firm Quality [63]

According to this view, that over the last decade become a new methodological approach to enterprise spatial planning, the socio-environmental systems, i.e. the territories $[63,64])$, considered as open systems and hardly conditioned by their internal relations (but also by the relations among the parts of different realities that interact with and between them) coincide with the geo-economic ones: local productive systems. 
In the case of local productive systems, the single firm can be assumed as a sub-system. Its relations with the territory determine the compatibility of its internal objectives with the development choices of the whole territorial economy. We can measure the effects produced by the enterprises' activities with regard to the need for conservation of a certain level of environmental quality. Environmental quality is considered indispensable to avoid irreversible changes of state in human and natural capital. This defines the local environmental dimension within which the enterprises have to operate to be sustainable (Figure 3).

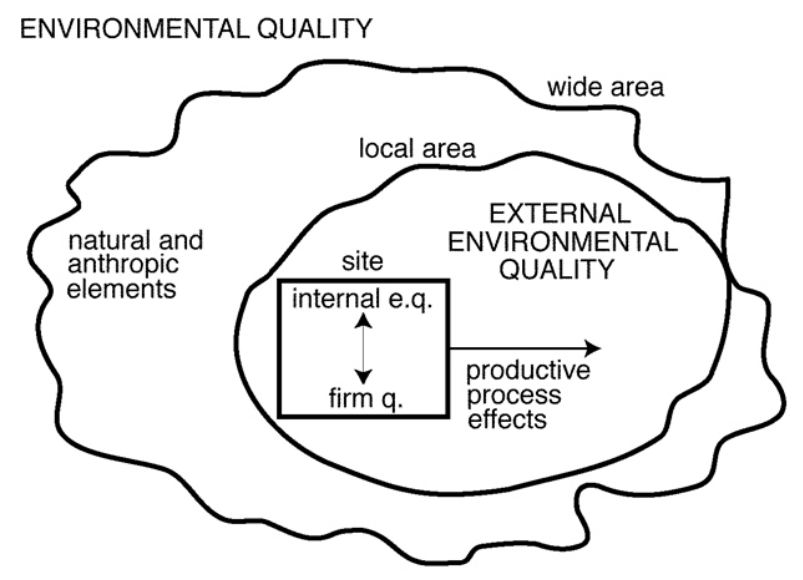

Figure 3. Environmental Quality dimension [64]

The Environmental Quality is a global concept, but it shows itself at the local scale. Aiming at the environmental analysis for the sustainability of production it is important to analyse the factors that influence the external environmental quality, and not simply relating to the production site (as in ISO framework), that is considered as a component of the enterprise management system.

So it is important to highlight that the present assessment of environmental and territorial management measures should be integrated with different competences, because the approach of the single firm - within which it is sufficient an Environmental Management System (EMS) ${ }^{16}$ based on Total Quality Environmental Management (TQEM) ${ }^{17}$ logic - should be completed with the dimension of the territorial strategic planning, that in Europe is considered a public task and service.

\footnotetext{
${ }^{16}$ Environmental Management System (EMS) is a systematic approach for incorporating energy and environmental goals and priorities (such as energy use and regulatory compliance) into routine operations. Environmental management system (EMS) refers to the management of environmental organization's programs in a comprehensive, systematic, planned and documented manner. It includes the organizational structure, planning and resources for developing, implementing and maintaining policy for environmental protection. The most popular EMS model are the ISO and the EMAS.

${ }^{17}$ Customer-focused management philosophy that seeks to continuously improve business processes using analytical tools and actively involving all staff. There are several models for TQM, EFQM, the Speyer, the Malcolm Baldrige, ISO 9004 are the most common.
}

This is why the firm, having internalised environmental sustainability, needs to find new external economies of scale.

This can only happen by changing or replacing the localisation factors present in traditional models.

For example, if we take into consideration the model developed by Smith [73] to calculate how firms can localize to achieve economies of agglomeration (space-cost curve), we see that he considers good prices as fixed, while varying total costs of transportation; localization choices depend on the distance (and its costs), in relation to the specific places that present suitable conditions for the settlement (capital, labour, material source, market) (Figure 4).

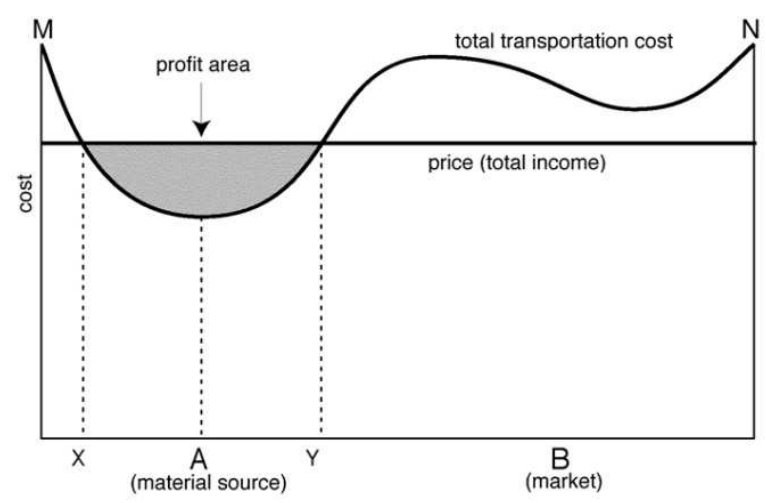

Figure 4. Smith's space-cost curve [49]

where: A represents the best localization (lower cost);

$\mathrm{X}$ and $\mathrm{Y}$ (the spatial limits of profit) delimit the profit area for firms

Nevertheless, if we introduce sustainability as a new relevant factor for enterprise localization the curve changes in consequence of the presence of a series of structures and infrastructures, shared by all firms in the development area and dedicated to the satisfaction of the needs of environmental management.

However, costs of realization and management of these territorial services are too high for a single firm, considering that more than $90 \%$ of European enterprises are small-medium and micro firms. These agglomeration costs should not be charged on the settled community (because of fairness reasons, and also because some of these structures are fully dedicated to production activities and to citizens), so some groups of small and medium firms decide to share urbanization costs of the area and to co-operate in order to take advantage of the economic gains deriving from territorial agglomeration.

Besides, the common localisation and management of environmental sustainability become essential if the settled production activities are different one from the other, as that they can only share few territorial infrastructures, but not the creation and maintenance of specific services, useful for specific kind of activities.

These empirical observations justify, also at a territorial level, the affirmation that the single firm cannot satisfy the requirements of productive sustainability by its own, but 
environmental management can be fully effective only if it is referred to territorial systems of integrated firms.

Localization costs, which are very high in the first phase of development because of the realization of the essential structures for production and environment management, decrease in time, especially in relation to the number of firms that participate to the activity of agglomeration. These bear the initial costs that are partially charged on the products prices, to cover a portion of the higher production costs deriving from the new needs for sustainability. This causes a positive change in selling prices (to grant the products environmental care), but also their decrease in the long term in relation to the higher number of firms that pay the common costs for environmental management.

So, reconsidering afore-mentioned Smith's model, the prices cannot be assumed as fixed, because they are influenced by the new logics of sustainability; but also the costs, that are fixed in theory as they are initially referred to structural realization, will change in relation to the agglomeration's dimension, because of the possibility to share them among all the present firms, but also for the influences of agglomeration economies and diseconomies on their trend.

The environmental management costs, and not the distance (and the transport costs), are considered in this case as the main factor for the localization choice, because this is a model of spatial concentration, so the problems of accessibility are minimized by the proximity among the different units of the general system of production.

Therefore, the main problem in localization choices of production, after the preliminary study of the area and of its environmental characteristics is to integrate them with the features of economic activities: then the focus is in identifying the right dimension of the sustainability area, that cannot be the optimum dimension for the creation of external economies, but rather the one suitable to bear environmental costs and responsibilities, near to the economic advantages of production growth (fig. 5).

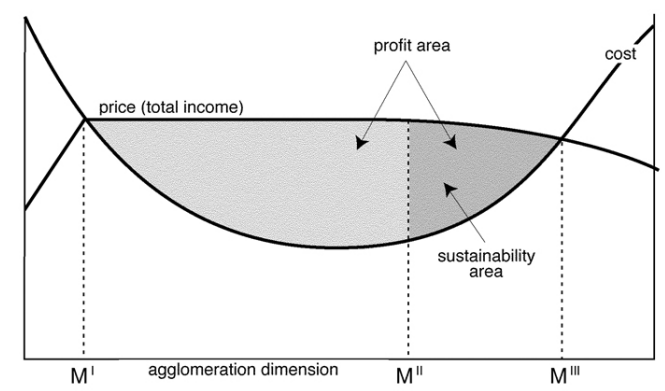

Figure 5. Industrial localization for sustainable production [64]

The two marked areas represent the concentration of a number of firms able to obtain positive external economies for production to allow economic efficiency and reintegration of costs. But only the smaller grey area identifies a sustainable situation, even if not an optimum state by an economic point of view, because it allows to integrate environmental needs with the ones of production, even if with some withdrawal.

The costs change in relation to the agglomeration economies and diseconomies, while the prices (not fixed), first increase, because of the initial costs for the settlement in the area, then, after a period of stability, decrease, because of the agglomeration advantages, that are determined by the dimension of the agglomeration and the improvement in the production economic efficiency.

The suitable localization area for firms (according to Smith) is represented by the spatial margins of profit M' and M"', while the sustainability area (M" - M"') is smaller because of the necessity to reach a determined agglomeration dimension, able to create particular external economies for environmental management, allowing the decrease of selling prices.

\subsection{An Evaluation Model for Competitiveness in Sustainability: Place-Based Evidence in Europe}

Models previously described, as well as the Lisbon 2000 and Gothenburg 2001 strategies, have changed the approach to economic and social policies of the European Union (competitiveness in sustainability). In that framework, principles of sustainability, cohesion and competitiveness oriented territories and enterprises behaviour, confirming the need of new determinants (Figure 1) in the calculus of the enterprises performance and development.

A dedicated methodology (STeMA) ${ }^{18}$ accompanied this process of integration to reinforce the localisation trend model of enterprises. It is finalised to receive the territorial effects of the European present and future policy about the re-launch of the enterprise systems and networks on the base of the European SMFs Chart [27] and the Europe 2020 Strategy, in regards to the objectives of Basel $2^{19}$.

The model is useful in order to assess appropriate financial and economic choices of the territorial government institutions regarding enterprise networks regional development.

In fact, STeMA makes it possible:

- to define the territorial "playground" for all regional-national enterprises' systems;

- to calculate the risk of compromising the territorial systems through a Territorial Impact Assessment (TIA) 20 procedure, with respect to the Lisbon/Gothenburg policies;

\footnotetext{
${ }^{18}$ STeMA (Sustainable Territorial environmental/economic Management Approach) $[65,66,67]$.

19 "Basel 2" is the international agreement on capital requirements for banks. According to it the banks of the acceding countries will have to set aside capital shares proportional to the risk arising from the various credit hired, evaluated through the instrument of the rating. In this section we give a brief but, hopefully, comprehensive information on the history of the Agreement, its writers and the actors, motives and expectations consequences of the agreement.

${ }^{20}$ Technical-administrative procedure aimed at the assessment by the competent authorities, the overall impact of the project of a work environment.
} 
- to select the trans-national/regional areas for developing co-operative competitiveness by the use of Structural Funds.

- $\quad$ to integrate Porter's diamond with four new composite indices that answer the competitiveness in sustainability's issues.

Table 1. European territorial dimension of entrepreneurship competitiveness by the revisited Porter Diamond and STeMA application [65]

Innovation \& Research: In this determinant the EU competitiveness of firms suggests that the European Investment Bank should take a leading role in promoting the networks required for innovation and research across the European Union. The updating is a priority which needs to be coordinated at the EU level, but devolved to lower agencies as regards local management. The proposed European innovation scoreboard would be introduced to have effect at the national/trans-national level, while it is at a regional level that 'innovation poles' should be established. In terms of support, a 'European Institute of Technology' could be set up at the EU level, but this and other European Technology Initiatives may be promoted by, and partnered with, industry and possibly higher education establishments.

Global/Local Interaction The Global/Local Interaction is fundamental to ensure labour market requirements are met, with agreement on increasing the mobility of the workforce and migration. This would be assisted by the establishment of a European Higher Education Area. The much contested reform of the European social model promoted by the Lisbon Agenda, basing support on work and alleviating tax pressures on labour, would be difficult to enforce at the EU level given past failed efforts to develop a genuine European social policy. Consequently the national scoreboard approach to improving labour participation rates and maximising productivity are probably the most attainable means of challenging perceived inefficiencies in the model. Meanwhile regional variations in work, tax and income maintenance configurations may offer alternative solutions to mitigating market inequities whilst retaining economic efficiency.

Quality: Addressing the issue of life chances is a key part of this determinant. However, here Lisbon objectives for firms are less specific, allowing future innovation in policy development at all levels. Suggestions include innovation in eco-technologies harnessed to enhancing quality of life and renewing neighbourhoods and introducing labour policies which address the conflicts arising from maintaining a healthy work/home life balance.

Resources and Funds: In this determinant there is again an emphasis on labour market and income maintenance policies. Given the nation state command of these areas the Commissions' targets for the increasing work force participation rates - by at least $9 \%$ - with particular emphasis on women and older workers are appropriately devolved to the scoreboard approach as embodied in the National Plans recently submitted. More flexibility in labour market conditions with the extensions of freedom of movement may however help create the conditions for this. Measures may be enacted at both the national and the EU level to foster an encouraging environment for private research investment, R\&D partnerships and high technology start-ups. These could be made more attractive by adjusting tax policies and providing the appropriate support in the form of venture capital with European Investment Bank backing. Finally at the macro level too, a reform of Structural Funds to focus on local employment delivery and economic growth, have been a controversial, but fundamental pillar of the Lisbon Agenda.
STeMA methodology assesses if and how a given territory and/or enterprise is able to generate/develop competitiveness, not in absolute terms but relatively to what Amartya Sen calls "capabilities". They are territorial capabilities and, as the territorial initial resources, play a key role in business competitiveness: their statistic-spatial measure is always territorialised.

The use of the quali-quantitative indicators that STeMA adopts to analyse entrepreneurship can more quickly and analytically respond to the increasingly insistent requests from politics, business, public administration and citizens.

Transformed into system and networks, the firm fortify the ties, connections and sharing of common services (information systems, real services), concurring to create its own and regional territorial capital, which represents the amount of natural and human resources that can be used in sustainability within a development and production process to be competitive.

The whole of these considerations brings to considerate the knowledge and the management of the territorial capital as a critical success factor for innovation and growth of regions and enterprises. In the follow it will be better explained the key factors for developing the territorial capital with regards to enterprises, and what role these factors play in achieving forms of competitiveness. New territorial organizations, as the polycentric ones, are able to aim at this scope.

\section{The Territorial Capital for the Enterprises' Local System and Networks}

Territorial capital, as the entrepreneurship capital too, was first proposed as a reference for the development process in a regional policy context by the Organisation for Economic Co-operation and Development [61]. As earlier explained (see note 7), it has been recently retrieved by DG Regio of the Commission of the European Union: "Each region has a specific 'territorial capital' that is distinct from that of other areas and generates a higher return for specific kinds of investments than for others, since these are better suited to the area and use its assets and potential more effectively. Territorial development policies (policies with a territorial approach to development) should first and foremost help areas to develop their "territorial capital" $[23,9]$.

Knowledge and management of the territorial capital can be seen as critical success factor for innovation and growth of regions and enterprises; this factor enhances the ability to manage information in order to appropriately identify and solve problems, or, more precisely in the economic domain, the ability to transform information and invention into innovation and productivity increase, through co-operative or market interaction. In contexts characterized by a plurality of agents - like cities or industrial districts knowledge evolution "is not the result of individual efforts in Research \& Development (R\&D) within individual firms, 
but rather the combination of complementary capacities and of widespread interactive learning processes, which involve many 'customers' and 'suppliers' along a well-defined filière or supply chain" [11: 307].

Elements making up a region's territorial capital can be divided into a) structural characteristics, and b) characteristics associated with its territorial position. These elements can be identified as a localised set of common goods, producing indivisible collective assets. They cannot be privately owned. They include: cultural, historical and environmental heritage, as specific and characteristic components of places. Looking for key factors for developing the territorial capital for enterprises, we discover:

1. Social, environmental, economic and cultural context which describes the general structural conditions, features and dynamics of the territory, as well as the favourable territorial preconditions for defining and implementing territorial governance actions (institutional confidence, innovative milieu, etc.);

2. Policies to describe the institutional frameworks of territorial policies, instruments and procedures for governance (i.e. the "governing" of governance);

3. Territorial governance actions, defined as the experiences, projects, programmes, etc., that need or stimulate a territorial governance approach, evaluating interconnected governance processes and results, at different levels.

4. ICT as whole of services concentrated in the urban areas and metropolitan agglomerations with different levels of accessibility and availability.

The role played by services of general interest and their full exploitation in urbanised regions is a fundamental source of attraction for direct foreign investments and improvement of the human and physical capital performances (especially in the enlargement countries).

For this reason, since the end of 1980 s and according to the growth literature, specific planning actions were launched in order to accelerate economic development in the lagging behind regions. The improvement of human capital [51] and the development of public infrastructures, such as transports, seemed to be able to increase the marginal product of private capital, fostering capital accumulation and growth $[2,5]$.

This was also the Economic geography point of view: new transport infrastructures seemed to increase accessibility, occasions of firms' location and, in this way, the attractiveness of regions and the employment $[55,82,56$, 71].

Now we know there is not a linear increase or de-crease between firms and regional infrastructural development; while, as some authors [8] had anticipated it is better to focus on the role of local agencies and local communities for addressing questions of equity in recruiting plans of industries and residents, and for promoting small businesses for job creation, broader tax basis, growth and development to sustain the community's quality of life and vitality.
Concerning the evaluation of the territorial dimension of competitiveness in sustainability, and also referring to the studies on the competitiveness of nations [62, 44, 42], the approach of macro-economic evaluation widened to the regional scale is able to be critically evaluated. Indeed, at the regional European scale, this approach cannot count on the same adjustment mechanisms, or on the completely independent fiscal systems that can be found at national level. For instance, such factors as 'knowledge and innovations', one of the Lisbon's policies, express all their criticality at the regional level only, where it is possible to evaluate their differences and changes across time and space [65].

The Lisbon's policies, renewed in main part within Europe 2020 Strategy, are directly related to: i) to extend and deepen the Internal Market; ii) to ensure open and competitive markets; iii) to improve regulation; iv) to expand and improve infrastructure; v) to invest in Research and Development; vi) to contribute to a strong industrial basis; vii) to increase employment and modernise social protection; viii) to improve adaptability and flexibility of the labour market; ix) to invest in education and skills.

The results of this revision suggest the assessment of territorial competitiveness as linked to sustainability, also from the externalities and internalities point of views (external and internal cooperation economies of scale).

Also the renovated Lisbon Strategy 2009 [24] more and more developed the dissemination of intelligent networks using ICT, suggesting to exploit network advantages at the European scale and to increase competitive gains of firms, especially as regards the manufacturing industry and Small and Medium Enterprises (SMEs); providing assistance to consumers to evaluate efficiency in terms of resources.

This approach would help the EU to relocate itself in a world of low carbon emission and resource-constrained, while avoiding environmental degradation, biodiversity loss and unsustainable use of resources, strengthening economic, social and territorial cohesion [26].

The better possible territorial organisation to realise this goal is polycentrism [18]. A polycentric, cohesive, competitive, sustainable and entrepreneurial region would have or seek to obtain [65]:

- a competitive market which uses internal and differentiated development factors, in respect of rules (governance) granting environmental, social, cultural and economic sustainability;

- $\quad$ the availability of key resources beneficial to business vitality and innovative factors acting within a stable social system;

- $\quad$ cooperative and subsidiary managerial capabilities, to inspire confidence towards the institutions;

- $\quad$ the capability to produce in a stable way the maximum possible added value (economic competitiveness) in the territory, enhancing the resources through local cooperation (social competitiveness);

- environmental values distinctive to the territory itself, whose active protection is granted by a renewable use 
of natural resources and wealth (environmental competitiveness);

- a high level of co-operative internal capacities, measurable in the ranking assigned by globalization (political competitiveness).

Finally, it is necessary to change the start-up of the development process. In fact, the better way to economic development is a bottom up (local) approach focused on local entrepreneurship by which endogenous factors provide the necessary condition for growth: the entrepreneur and human capital are important factors for local development. In stressing the role of individuals- to which the one of institutions must also be added -, the bottom-up approach seeks to broaden community involvement in regional development; it also values local participation and endogenous inputs with regards to action, policies and institutional behaviour.

Anyway, all systems are characterized by an operative structure and a government body, and territory is a system (conceptualized also as a service system for enterprises), as a consequence the necessity of territorial governance arises. The crucial question is about the government body which has the responsibilities about strategic decisions. Enterprises as accomplished viable systems can simply identify always a specific decision maker; instead in the viable system territory the government decisions are more articulated and fragmented among different logical levels. That's way the territorial decision making is performed in a network perspective. These territorial aspects (inputs) can be transformed in rules of territorial governance, useful to make local entrepreneurship more competitive.

\section{Territorial Governance and Enterprise Governance: What Meeting Point between Real Economy and Conceptual Revision}

Governance, defined as a set of rules, helps to utilize and develop a common milieu - cohesion - which allows both to achieve strategic objectives and to transfer within firms and territory the choices of political-institutional and corporate actions, and to set-up a shared model of compliance.

Territorial governance is the process of territorial organisation of the multiplicity of relations that characterize interactions among actors and different, but not irreconcilable, interests. This organisational dimension refers to the construction of a shared territorial vision, based on the recognition and valorisation of the territorial capital to create sustainable territorial cohesion at different levels. In other words, territorial governance is the condicio sine qua non to guarantee more balanced development across Europe and to achieve territorial cohesion. In summary, territorial governance can be defined as the process of organization and coordination of actors to develop territorial capital in a non-destructive way in order to improve territorial cohesion at different levels.
Paraphrasing the terms of corporate/enterprise governance, territorial governance transfers at local level the relations among board (the public institution), management (the administrative-management system), shareholders (the citizens), clients (employees - business and citizens) and stakeholders (interest holders). Although not always pursuing identical goals they are all the same aiming at enhancing external scale economies (conceived as urban scope economies), economic relations, stability and reliability on markets and international investment flows.

The territorial governance of firms and for firms allows for the free unfolding of local competitive potential, whose enhancement is realized through shared projects and rules, triggered by the ability of the institutions (public and private) to create the "network" to configure the necessary skills/resources to be competitive in sustainability.

Since 2007, governance contributes to enhance different territorial contexts, assessing ex-ante their degree of cohesion with respect to competitiveness, assuring stability (static approach inside the countries), convergence (dynamic-comparative approach among indicators), enhancement of general life quality for the European population, and positive regional performance in terms of employment, income, productivity, by single word: regional capability. Territorial and enterprise governance have a special prominence in a context where the capability to be competitive in different areas and territories increasingly depends, besides the agglomerations processes of the activities realized over time, on the capability to exploit existent resources and competences, through an adequate use of networking.

The European Union recognizes in its political orientation the need for firms to adapt, as much as possible, to the rules aiming at promoting sustainability in all its forms, in order to build an economic and social model more and more suitable to combine productivity and social cohesion with sustainability itself.

Only since 2004, firms have actually been facing the issue of sustainability and the closely related theme of competitiveness, causing a shift in the business world of tangible factors - such as allocation of resources, labour costs, plants and equipment, etc. - and intangible assets as, for example, knowledge creation, exchange of know-how, economies of proximity, relations with the institutions and the opportunities provided by new systems of local governance

The growing importance give to the theme of sustainability as a strategic and localization factor is observed within the regional strategic plans, inducing the local production systems to invest and engage in this direction, leading to the determination of a territorial development model based on the endogenous potential and measured in terms of sustainability.

Territorial development and territorial competitiveness are strongly linked to firms' behaviour and interdependencies.

The combination of these factors creates the regional 
competitiveness shown by the "pyramidal" model of "regional competitiveness" suggested by Martin [57], whereby it is possible to analyse separately the resources of competitiveness (or "competitiveness revealed") on the one hand, and the results-targets, especially in terms of improvement of the quality of life, on the other.

Firms, for example, are invited to join the Global Compact $^{21}$ in relation to the areas of human rights, working conditions and environment, encouraged to engage effectively in defending human rights worldwide, in the fight against poverty and illiteracy, in the protection of environment, in the respect of workers' rights, in the protection of historical and cultural heritage of communities.

In the new global economy, in fact, a more than advantageous result would be for firms to embrace the principles of the Global Compact and put them consistently into practice ("it makes good business sense"), as repeatedly stressed by the European Commission.

The "Europe 2020" Strategy, under development by the EU to combat the crisis and reposition Europe among the poles of world economy, suggests three lines of priority investment' which mutually reinforce:

- Smart growth: developing an economy based on knowledge and innovation, improving quality of education, strengthening research, promoting innovation and transfer of knowledge throughout the EU, so that innovative ideas are transformed into new services that stimulate growth, create quality jobs and contribute to addressing the challenges of European and global society;

- Sustainable growth: promoting a more efficient economy in terms of resources, more eco-friendly and more competitive;

- Inclusive growth: promoting an economy with a high rate of employment that favours social and territorial cohesion.

With regard to regional policy for new entrepreneurship, the main goal at urban behaviour's scale is the territorial cohesion. This measure has often been carried out through different mark indicators, sometimes out of synch in time, thus creating a wide gap between empirical experiences at local scale and regional territorial policies. This phenomenon is studied and disassembled, so that it can be studied separately from the subsidiary relation that cohesion has to observe in the administration field (multilevel governance), too.

It increases or decreases with other phenomena: labour market, social disease, marginalization and social exclusion, explosion and diversification of mobility/accessibility, urban and territorial regulation and regeneration.

Therefore regional cohesion depends and is shaped by the transformation of original localisms into local systems in

\footnotetext{
21 The document was intended to obtain, in 2002, support by 100 corporations and 1,000 other firms in the world. It provides that firms, motivated by a strong sense of social responsibility, should be a valuable resource for the whole community and for the international community..
}

many European regions.

Different sources pay attention to this capability that is due to:

- $\quad$ competition increasing at international level;

- $\quad$ processes' growth of production de-localization;

- propensity towards faster innovation of process, product and organization, due to new technologies' implementation (ICT).

Cohesion's territorial dimension is always represented by a local collective interest. Where local cohesion is stable for at least a decade (as in periurban areas) environmental values are detected higher and more lasting, as well as chances for endogenous investments beyond the city (as in Italy's North-East); when cohesion's attraction fades, phenomena appear as quality loss, functionality lack, rejection of pursuing exogenous economic objectives.

The city, rather than the territory, emerges as a two speed cohesion vehicle for enterprises. This is measurable in all Fordist and post-Fordist cities, where segregation is nevertheless "joined" by strong class solidarity and socialization capability, due to the small size of mobility areas.

In order to recompose this de-structured vision, according to models of the end of last century, enterprises and institutions contributed to realize a connected fabric organized on three elements:

1. internal accessibility (average mobility time less than 1 hour, diversification and specialization of activities, complete supply of goods, complex complementarities organized in network)

2. presence of interconnection nodes of differentiated networks, which would grant access to external nodes of the global system

3. self-organization, which leads to a strongly inter-connected landscape, where mobility areas are large and synchronized (as suggested by the Netherlands experience).

It seems possible to customize polycentric cohesive patterns in terms of the home-work relation, leaving the individual freedom of building a city "à la carte" to substitute to the Fordist integration and post-Fordist disintegration.

Cohesion is represented and measured by several regions where economic and social life is directly affected by sufficient intra-border/trans-border integration and inter-dependencies ${ }^{22}$. These highlight macro-economic and infrastructural features, as well as capability in achieving

\footnotetext{
22 These measure and representation is made by Nomenclature of Territorial Units for Statistics (NUTS) .It is a hierarchical system for dividing up the economic territory of the EU for the purpose of:

- The collection, development and harmonisation of EU regional statistics.

- Socio-economic analyses of the regions.

- NUTS 1: major socio-economic regions (countries)

- NUTS 2: basic regions for the application of regional policies (administrative regions)

○ NUTS 3: small regions for specific diagnoses (sub regional areas)
} 
local integration ${ }^{23}$. In this perspective, cohesion was also intended as a variable of global competition among internationalized territories, where economic concentration creates hierarchies among enterprises and enterprise networks, nowadays important for how territories could turn themselves into active subjects of development.

\section{Relationships between Enterprise and Regional Development towards 2020}

In order to answer to effects of the global crisis in compliance with the Europe 2020 goals, the integration of cohesion, competitiveness, sustainability in national and regional policies including enterprises is a clear emerging need in Europe.

From the territorial point of view as well as following a European vision, for achieve this integration it is necessary to pursue the development of endogenous regional productive models, able in progress to increase the participation of the enterprise systems and networks towards new generations of development.

The contribution of Economic Geography to shape enterprise policies, in particular in European ones, highlights some scientific questions relative to: 1) territorial capital as the main factor for managing impacts and effects of the competitive growth by offering endogenous and sustainable solutions; 2) the capacity of European policy to achieve these goals by means of general directives and common methodologies and procedures; 3 ) the potential of territorial dimensions to generate a competitive reaction of enterprises by translating general directions in endogenous place-based strategies.

In relation to a more economic development approach and in the European context, the degree of inclusion of the territorial dimension (in terms of place based approach and capability) within the enterprise policies aims at competitiveness and sustainability (Lisbon/Gothenburg Strategy ex ante evaluation)

Again in relation to a more integrated development approach, the territory concept could be revisited to reflect also on decision making process of enterprises, recovering the gap between the regional adaptive capability and goals of the competitiveness re-launch through Europe 2020 Strategy [25]. The introduction into the traditional model of localization of new elements appears a useful way to integrate and update the current strategic vision of enterprise behaviour.

The reference to the local scale becomes important as it implies the idea that enterprise policies must be focused, before attracting international capital, on keeping a

\footnotetext{
${ }^{23}$ Cohesive areas receive and get out great flows inside themselves and towards urban and productive centres, by organizing their daily directionality, like in Swiss Cantons and some Netherlands' regions, or their linear transit in trans-border cases.
}

favourable environment for domestic business growth. As a result of these theoretical insights, the "territorial" competition becomes the "objective" of the territorial policies, which regions have to develop in a globalization context.

\section{Acknowledgments}

Authors thank for scientific critical suggestions received by European Economic Geography and Economics and Business fields during the writing and the revision of the paper.

\section{References}

[1] Aghion P, Howitt P.(1993) A model of growth through creative destruction. Econometrica, 60, 323-51.

[2] Aschauer D. (1989) Is public expenditure productive?. Journal of Monetary Economics, 23, 177-220.

[3] Arrow, Kenneth J. 1962. The economic implications of learning by doing. Review of Economic Studies 29, 3: $155-73$

[4] Aw B.Y., Hwangi A. (1995) Productivity and export marker: a firm level analysis. Journal of Development Economics, 47, 209-231.

[5] Barro J. R. (1990) Government spending in a simple model of endogenous growth. Journal of Political Economy, 20(2), 221-247.

[6] Brander J., T. Lewis (1986) Oligopoly and financial structure: the limited liability effect. American Economic Review, 76, 956-70.

[7] Brennan M., Kraus A. (1987) Efficient financing under information asymmetric. Journal of Finance 42, 1224-1243.

[8] Bryant C. R., Preston R. E. (1990) Economic Development in Small Town and Rural Environments. Economic Development Bulletin, 10.

[9] Camagni R. (2008). Regional competitiveness: towards a theory of territorial capital. In: R. Capello, R. Camagni, P. Chizzolini and R. Frasati, eds. Modelling regional scenarios for the enlarged Europe: European competitiveness and global strategies. Berlin: Springer-Verlag, 33-47.

[10] Capello R., Carangiu A., Nijkamp P. (2009), Territorial Capital and Regional Growth: Increasing Returns in Cognitive Knowledge Use. Tinbergen Institute Discussion Paper 09-059/3.

[11] Cappellin R. (2003). Networks and Technological Change in Regional Clusters. In Bröcker J., Dohse D. and Soltwedel R. a cura di., Innovation Clusters in Interregional Competition. Berlin, Springer, 53-78.

[12] Cass David (1965), Optimum growth in an aggregative model of capital accumulation. Review of Economic Studies 32, 3: 233-40.

[13] Cheshire P.C., Gordon I.R. (1996) Territorial Competition and the Predictability of Collective (In)Action. International Journal of Urban and Regional Research, 20(3), 383-399. 
[14] Chertow M., Lifset R. (2008) Industrial symbiosis. Encyclopedia of Earth. Available on http://www.eoearth.org/article/Industrial_symbiosis. Last access $6^{\text {th }}$ of November 2013.

[15] Cheshire P.C., Gordon I.R. (1998) Territorial Competition: Some Lessons For Policy. Annals of Regional Science, 32, 321-346.

[16] Clerides S.K., Lach S., Tybout J.R. (1998) Is lesrning by exporting important? Microdynamic evidence from Colombia, Mexico, and Morocco. The Quarterly Journal of Economics, 113(3), 903-947.

[17] Costantinides G., Grundy B. (1989), Optimal investment stock with repurchase and financing as signals. Review of Financial Studies, 445-465

[18] Davoudi S., Strange I. (2009) Conceptions of Space and Place in Strategic Spatial Planning, Routledge, London.

[19] Casey J. Dawkins (2003), Regional Development Theory: Conceptual Foundations, Classic Works, and Recent Developments, Journal of Planning Literature, Vol.18, No.2

[20] Delgado M.A., Farinas J.C. (1999), Firm's productivity and export markets: a nonparametric approach. Mimeo.

[21] Dixit A., Pindyck R. (1994). Investment under uncertainty. Princeton University Press, Princeton.

[22] European Communities (2003), European Competitiveness Report, CEC (2003)1299. Final. Brussels.

[23] European Commission (2005) , Implementation of the Lisbon Partnership for Growth and Jobs The Contribution of Regions and Cities, DI CdR 45. Final Brussels.

[24] European Commission (2009), The implementation of the Lisbon Strategy. Bruxelles.

[25] European Commission (2010), Europe2020, a strategy for an intelligent, sustainable and inclusive growth. Available on $\mathrm{http}: / /$ ec.europa.eu/europe2020/index_en.htm. Last access $6^{\text {th }}$ of November 2013

[26] European Commission (2010), Fifth Report on Economic, Social and Territorial Cohesion, $\operatorname{COM}(2010) 642$. Final. Bruxelles.

[27] European Commission (2005)The New SME Definition: User Guide and Model Declaration European Commission Publications Office, Luxembourg

[28] European Council of Gothenburg (2001), Presidency conclusions, 15-16 June. Gothenburg.

[29] European Council of Lisbon (2000), Presidency conclusions, 22-23 march. Lisbon.

[30] European Council (2007), Territorial Agenda of the European Union. Towards a more competitive and sustainable Europe of diverse regions, Informal Ministerial Meeting on Urban Development and Territorial Cohesion, 24-27 May, Leipzig.

[31] European Council (2011), Territorial Agenda of the European Union 2020 - Towards an Inclusive, Smart and Sustainable Europe of Diverse Regions, Informal Ministerial Meeting for Spatial Planning and Territorial Development on 19th May 2011 Gödöllö, Hungary.
[32] Graham E.M., Krugman, P.R. (1993), The surge of foreign direct investment on the 1980s. In K. Froot a cura di. Foreign direct investment. The University of Chicago Press Chicago

[33] Grossman S., Hart O. (1982), Corporate Financial Structure and Managerial Incentives. In Corporate Financial Structure and Managerial Incentives, $107-140$.

[34] Harris M., Raviv A. (1988), The Theory of Capital Structure. The Journal of Finance, 46(1), 297-355.

[35] Helleiner G.K.. (1989) Transnational corporations and direct foreign investment. In Chenery and T.N. Srinivasan, a cura di. Handbook of Development Economics, vol. III, Cap. 27

[36] Hoover E. M. (1937). Spatial price discrimination, Rev. Econ. Stud. 4, 182-191

[37] Isard W. (1956), Location and Space-Economy: A General Theory Relating to Industrial Location, Market Areas, Land Use, Trade and Urban Structure, Cambridge (ma), The mit Press,.

[38] Jensen M. Michael C. (1986), Agency Costs of Free Cash Flow, Corporate Finance and Takeovers. American Economic Reuiew, 76, 323-29.

[39] Jensen M. (1988) Takeovers Their Causes and Consequences. The Journal of Economic Perspectives, Vol. 2(1), 21-48.

[40] Jensen M.C, -Meckling W.H., 1976, Theory of the Firm: Managerial Behavior, Agency Costs and Ownership Structure, The Journal of Financial Economics, 3, 305-360.

[41] Jørgensen J., Steineke J. M., Copus A., Prezioso M., Hanes N., Al-Assis., Lennert M. (2006) Literature review on regional growth, competitiveness. In: Lennert M., ed, Territorial impacts of EU economic policies and location of economic activities, 136-160.

[42] Kok W. (2004) Facing the Challenge. The Lisbon Strategy for growth and employment. Bruxelles. Final

[43] Koopmans Tjalling C. (1965), On the concept of optimal economic growth. In The econometric approach to development planning. Pontificae Academiae Scientiarum Scripta Varia No. 28. Amsterdam: North Holland.

[44] Krugman P. (1995) Development, Geography and Economic Theory. Cambridge MIT Press,.

[45] Leech D., Leahy, Ownership Structure (1991) Control Type Classifications and the Performance of Large British Companies. The Economic Journal. Vol. 101, 1418-1437

[46] Lennert M. (2006), Territorial impacts of EU economic policies and location of economic activities, Final Report, Bruxelles.

[47] Lennert M. (2010), Future orientation for cities, ESPON project FOCI, Luxembourg. Available on http://www.espon.eu/main/Menu_Projects/Menu_AppliedRe search/foci.html. Last access 6th November 2013

[48] Lipschitz L., Mc Donald D. (1991), Real Exchange Rates and Competitiveness - A Clarification of Concepts, and Some Measurements for Europe", IMF Working Papers 91/25, International Monetary Fund 
[49] Lloyd, P. E., Dicken, P. (1986), Spazio e localizzazione. Un 'interpretazione geografica dell'economia. Milano, Franco Angeli

[50] Lombardi D. R., Laybourn P. (2007) Industrial Symbiosis in Action. Report on the Third International Industrial Symbiosis Research Symposium Birmingham, England, Yale School of Forestry \& Environmental Studies.

[51] Lucas R. E. Jr. (1988) On the mechanics of economic development. Journal of Monetary Economics, 22, 3-42.

[52] Maksimovic V. (1988) Optimal capital structures in repeater oligopolies. Rand J. Econ, 19, 389-407.

[53] Markusen J. R. (1992) The Boundaries of Multinational Firms and the Theory of International Trade. Journal of Economic Perspectives, 9, 169-189.

[54] Marshall A. (1922), Principles of Economics, London. Macmillan.

[55] Martin P., Roger C. A. (1995) Industrial Location and Public Infrastructures. Journal of International Economics, 39, 335-351.

[56] Martin R. (1999) The new 'Geographical Turn' in Economics Some critical reflections. Cambridge. Journal of Economy, 23: 65-91.

[57] Martin R. (2005), Thinking about regional competitiveness: critical issues, Background 'Think-Piece' Paper. Available on

http://didattica.unibocconi.it/mypage/upload/48731_201006 01124105 RONMARTINPAPER1.PDF. Last access $6^{\text {th }}$ November 2013

[58] Mc Connel J., Servaes H., (1990) Additional evidence on equity ownership and corporate value. Journal of Financial Economics, 27, 595-612. Berlin, Springer.

[59] Nickell S. (1995) The Performance of Companies. Oxford Basil Blackwell.

[60] Nickell S. and Nicolitsas D. (1999) How does Önancial pressure affect Firms? European Economic Review, 43, $1435-1456$

[61] OECD (2001), Territorial Economy, Territorial Outlook. Available on: http://www.vwl.tuwien.ac.at/hanappi/AgeSo/SecReps/Territ orial_Outlook_F.pdf. Last access $6^{\text {th }}$ November 2013

[62] Porter M. E. (1990) The Competitive Advantage of Nations. New York, Free Press.

[63] Prezioso M. (1996) Small-medium firms advanced services. Green Quality and Economic-territorial model of localization. In Proceeding of Regional Science Association 36th Congress, Zurich.

[64] Prezioso M. (2001) Modello di organizzazione territoriale per la gestione della qualita' ambientale della produzione. In Calafiore G., Palagiano C., Paratore E., eds, Atti del XXVIII Congresso Geografico Italiano 3, 2921-2943. Roma, Epigeo

[65] Prezioso M. (2006) Territorial dimension of Lisbon-Gothenburg strategy, Espon 3.3 Project Final Report. Available http://www.espon.eu/export/sites/default/Documents/Project s/ESPON2006Projects/CoordinatingCrossThematicProjects/
LisbonStrategy/fr-3.3 final_25-01-2007.pdf . Last access $6^{\text {th }}$ of Novembre 2013

[66] Prezioso M. (2008) Is it possible to give more relevance at territorial dimension onto competitive and sustainable policy choices? Transition Studies Review, 15(1), 1-32.

[67] Prezioso M. (2010) The Sustainable Territorial environmental/economic Management Approach to manage global policy impacts and effects. In Cancilla, R., Garganos M., eds. Global Environmental Policies: Impact, Management and Effects, Hauppauge (NY), Nova Science Publishers, 110-163.

[68] Prezioso M., Renzetti P. (1999) Organizing model for sustainable small and medium firms The Italian case study. In Proceedings of European Regional Science Association 37th Congress. Dublin.

[69] Ramsey, Frank. 1928. A mathematical theory of saving. Economic Journal 38, 152: 543-59.

[70] Noe R. A. (1988). An investigation of the determinants of successful assigned mentoring relationships. Personnel Psychology, 41, 457-479.

[71] Puga D. (1999) The Rise and Fall of Regional Inequalities. European Economic Review, 43, 303-334.

[72] Ross S. A. (1976) Options and Efficiency. Quarterly Journal of Economics

[73] Schumpeter, Joseph (1934), The theoryof economic development. Cambridge, MA: Harvard University Press

[74] Schumpeter, Joseph. (1947) Capitalism, socialism, and democracy. New York: Harper.

[75] Scott A.J. e Storper M. (2003) Regions, Globalization, Development. Regional Studies, 37, 579-593.

[76] Short H., (1994) What makes firms perform well? European Economic Review. 41 (3-5), 783-796.

[77] Stiglitz J.E., Weiss A. (1981) Credit rationing in markets with imperfect information. The American Economic Review, 71 (3), 393-410.

[78] Stulz R. (1988) Managerial control of voting rights: Financing policies and the market for corporate control. Journal of Financial Economics, 20, 25-54.

[79] Smith D.M. (1966), A Theoretical Framework for Geographical Studies of Industrial location. Economic Geography, 42, 95-113.

[80] Stein J.C. (1992) Herd on the Street: Informational Inefficiencies in a Market with Short-Term Speculation. Journal of Finance, 47, 1461-1484.

[81] Titman S., (1984), The effect of capital structure on a firm's liquidation decision. Journal of Financial Economics, 13, 137-151

[82] Vickerman R. W. (1996). Restructuring of transport networks. EUREC, 3(96), 16-26.

[83] Vickers J., (1995) Competition and regulation in vertically related markets. Review of economic studies. Vol. 62/95, Oxford, Blackwell Publishers 
[84] Wagner J. (1994) The post-entry performance of new firms in German manufacturing industries. Journal of Industrial Economics, 92, 141-154.
[85] Weber A. (1929) Theory of the location of industries. Chicago, University of Chicago Press. 